\title{
An Anatolian study on the current knowledge and attitudes of urology operating room staff on ionizing radiation
}

\author{
Reha Girgin* (1)
}

\begin{abstract}
Background: To evaluate current approaches to ionizing radiation by personnel working in urology operating room at all levels of health service in Anatolia, Turkey.

Methods: A questionnaire was e-mailed to urology operating room personnel including MDs at different academic levels, between August and September 2020 in Anatolia, Turkey. The questionnaire included demographic questions and questions about ionizing radiation, exposure and protection.

Results: Of the 173 (11.9\%) respondents, 44.5\% were doctors, 24.9\% were nurses, 20.8\% were radiology technicians, and $9.8 \%$ were other operating room personnel. While most participants (73.4\%) had some knowledge of radiation, only $42.2 \%$ stated they had received radiation-specific training. The two most commonly used personal protective equipments (PPEs) among respondents (79.8\%) were lead aprons and thyroid protectors. Interestingly, both types of PPE were preferred among those who had not received radiation safety training. Conversely, besides lead aprons and thyroid protectors; gonadal protection, goggles and gloves were the preferred PPEs among respondents who had received radiation training $(p<0.001)$. Radiology technicians exhibited the highest compliance rate for dosimeter usage (100\%), followed by faculty members (37.5\%), urology specialists (36.7\%) nurses (27.9\%), operating room staff $(17.6 \%)$ and assistants (15\%). While differences in compliance were statistically significant $(p<0.001)$, no significant relationship was found between radiation protection measures and years of experience, daily fluoroscopy exposure or education level.
\end{abstract}

Conclusions: Despite advances in medical science, our findings suggest that many hospital personnel are still insensitive to the dangers of fluoroscopy, which is of great importance in urology operating rooms.

Keywords: Ionizing radiation, Urology operating room, Awareness

\section{Background}

As technologies continue to develop, more physicians are performing minimally invasive surgeries [1]. Among the minimally invasive methods performed, fluoroscopy, which is simple to use and interpret, is a commonly practised and preferred imaging technique in the field of urology $[1,2]$. However, the major disadvantages

*Correspondence: mujdereha7477@hotmail.com Department of Urology, Medical Faculty, Zonguldak Bulent Ecevit University, Zonguldak, Turkey of fluoroscopy are the dangers of ionizing radiation, to which all operating room personnel are exposed during fluoroscopy procedures [1].

The International Radiation Commission recommends that, in a 5-year period, professional groups should not exceed $20 \mathrm{mSv} /$ year [3]. Exceeding this limit can have serious consequences, which vary depending on radiation dose, duration and whether personal protective devices are used [1].

Despite an understanding of radiation and its harmful effects, there is inadequate coordination of operating 
room staff in the use of and protection against radiation due to fluoroscopy usage. In both Turkey and worldwide, various studies have examined the dangers of inadequate radiation protection methods among endourologists, urology operating room staff members, medical students and urology residents [4-8]. To date, no Turkish study has simultaneously compared radiation safety compliance among urology staff at all levels over the same period of time. Therefore, this study surveyed personnel working at all levels in urology in Anatolia, Turkey, to evaluate their current approaches to ionizing radiation.

\section{Methods}

Research ethics for this study was approved by Zonguldak Bulent Ecevit University local ethics committee (BLINDED FOR PEER REVIEW). A questionnaire was e-mailed to 1453 urology operating rooms personnel including MDs at different academic levels, nurses, medical staff and radiology technicians. Our survey captured respondents working at various hospitals (i.e. state, private, academic and medical facilities) at different Anatolian regions between August and September 2020. Google Docs ${ }^{\mathrm{TM}}$ was used to prepare the survey form as it also ensured participants' anonymity. Furthermore, participants were informed that the results of the questionnaire would be used for scientific purposes only.

The survey comprised 15 questions and evaluated participants' demographics such as age, profession, educational status, duration in the profession and their institution of employment. The questionnaire also interrogated participants' knowledge about the harmful effects of radiation, their daily fluoroscopy exposure, whether they received radiation-specific training, possess a dosimeter, use personal protective equipment (PPE) and have a warning sign posted in the appropriate work areas.

The survey used in this study was adapted from the questionnaire used by Tok et al. (1) but has not yet been validated. To determine the sample size for this study, power was taken at least $80 \%$ and $5 \%$ type 1 error for each variable. Descriptive statistics for categorical variables in our study were expressed as numbers and percentages, and the Chi-square test was used to determine the relationship between categorical variables. A significance level $(\alpha)$ of $5 \%$ was used, and the SPSS statistics package program (IBM SPSS for Windows, ver.24) was used for calculations.

\section{Results}

Fully completed questionnaires were returned by 173/1453 participants (11.9\%), of which 77 (44.5\%) were doctors of different academic levels, 43 (24.9\%) were nurses, 17 (9.8\%) were auxiliary healthcare personnel, and 36 (20.8\%) were radiology technicians. Respondents ranged in age from 24 to 63 years old, with the average age being $38.9 \pm 9.6$ years old. With respect to their highest level of education, 136 respondents (78.6\%) graduated from university, 24 (13.9\%) completed a 2-year associate degree, and $13(7.5 \%)$ completed either primary or high school. Other demographic data are shown in Table 1. Most of the participants were staffed at public (33.5\%) and university (29.5\%) hospitals. Most staff members used fluoroscopy at least once daily (39.3\%), and the intensive usage rate was substantial (37.0\%). In terms of their experience working in urology operating rooms, 27 participants $(15.6 \%)$ stated that they had been working for 1-5 years, 33 (19.1\%) for 6-10 years and 113 (65.3) for more than 10 years.

Following fluoroscopy procedures, 75 (43.4\%) participants stated that they used dosimeters and $44.5 \%$ of the participants took monthly and annual measurements. Notably, $31.4 \%$ of personnel working in university hospitals and $55.2 \%$ of those working in training and research hospitals stated that they used dosimeters. In contrast, $80.8 \%$ of the participants from private hospitals did not $(p=0.001)$.

Statistically significant differences in dosimeter usage were observed among healthcare workers and staff $(p<0.001)$. Specifically, compliance rates for dosimeter

\section{Table 1 Demographic characteristics of participants}

\begin{tabular}{|c|c|c|c|}
\hline Questions & Answers & $n$ & $\%$ \\
\hline \multirow[t]{2}{*}{ Gender } & Male & 122 & 70.5 \\
\hline & Female & 51 & 29.5 \\
\hline Mean age & $38.9 \pm 9.6$ & & \\
\hline \multirow[t]{6}{*}{ Job } & Urology specialists & 49 & 28.3 \\
\hline & Nurses & 43 & 24.8 \\
\hline & Radiology technicians & 36 & 20.8 \\
\hline & Assistants & 20 & 11.6 \\
\hline & $\begin{array}{l}\text { Auxiliary healthcare person- } \\
\text { nel }\end{array}$ & 17 & 9.8 \\
\hline & Faculty members & 8 & 4.6 \\
\hline \multirow[t]{3}{*}{ Level of education } & University & 136 & 78.6 \\
\hline & 2-year associate degree & 24 & 13.9 \\
\hline & Primary or high school & 13 & 7.5 \\
\hline \multirow{3}{*}{$\begin{array}{l}\text { For how long (years) have } \\
\text { you worked in a urology } \\
\text { surgery room? }\end{array}$} & 1 to 5 years & 27 & 15.6 \\
\hline & 6 to 10 years & 33 & 19.1 \\
\hline & More than 10 years & 113 & 65.3 \\
\hline \multirow[t]{4}{*}{ Your corporation } & State hospital & 58 & 33.5 \\
\hline & Private hospital & 26 & 15.0 \\
\hline & University hospital & 51 & 29.5 \\
\hline & $\begin{array}{l}\text { Training and research } \\
\text { hospital }\end{array}$ & 38 & 22.0 \\
\hline
\end{tabular}


usage among radiology technicians were $100 \%, 37.5 \%$ for faculty members, $36.7 \%$ for urology specialist, $27.9 \%$ for nurses, $17.6 \%$ for auxiliary healthcare personnel and 15\% for assistants. When asked if they were aware of the dangers of radiation, 127 participants $(73.4 \%)$ responded in the affirmative. Only 58 (42.2\%) participants stated they had received radiation-specific training, while $88.9 \%$ of radiology technicians received such training regularly.

As outlined in Table 2, responses to the question "Which system(s) are affected by radiation?" were not influenced by age, gender or the length of employment. In contrast, however, variables such as profession, education level and institution each influenced the respondents' answer to this question. Responses to the question "Which disease(s) are caused by radiation?" were significantly associated with participants' profession, gender, education level and the year in the profession $(p<0.05)$. No statistically significant difference was observed among participants who were educated about radiation dangers versus those who were not $(p>0.05)$.

Lead aprons and thyroid protectors were the most commonly used PPEs among respondents (79.8\%), and both types of PPE were preferred among those who had not received radiation safety training. Conversely, besides lead aprons and thyroid protectors gonadal protection, goggles and gloves were the preferred PPEs among respondents who received radiation training $(p<0.001)$, although no difference was observed between occupational groups. When asked if there were radiationspecific warning signs posted in fluoroscopy procedure

Table 2 Other questionnaire responses by participants

\begin{tabular}{|c|c|c|c|}
\hline Questions & Answers & $n$ & $\%$ \\
\hline \multirow[t]{4}{*}{ Average number of fluoroscopy exposures per day? } & 1 & 68 & 39.3 \\
\hline & 2 & 27 & 15.6 \\
\hline & 3 & 14 & 8.1 \\
\hline & $>4$ & 64 & 37.0 \\
\hline \multirow[t]{2}{*}{ Do you have a dosimeter? } & Yes & 75 & 43.4 \\
\hline & No & 98 & 56.6 \\
\hline \multirow[t]{2}{*}{ Are your dosimeter measurements taken regularly? } & Yes & 77 & 44.5 \\
\hline & No & 96 & 55.5 \\
\hline \multirow[t]{2}{*}{ Do you have enough information about the undesirable effects of radiation? } & Yes & 127 & 73.4 \\
\hline & No & 46 & 26.6 \\
\hline \multirow[t]{5}{*}{ Which systems or systems does the radiation affect? } & Central nervous system & 104 & 16.2 \\
\hline & Gastrointestinal system & 101 & 15.7 \\
\hline & Haematological system & 150 & 23.4 \\
\hline & Skin & 150 & 23.4 \\
\hline & Eyes & 137 & 21.3 \\
\hline \multirow[t]{7}{*}{ What disease or illnesses does radiation cause? } & Cancer & 172 & 38.7 \\
\hline & Cataract & 94 & 21.2 \\
\hline & Dementia & 49 & 11.0 \\
\hline & Leukaemia & 120 & 27.0 \\
\hline & Thyroid pathology & 4 & 0.9 \\
\hline & Infertility & 4 & 0.9 \\
\hline & Colitis & 1 & 0.2 \\
\hline \multirow[t]{2}{*}{ Have you been educated about the negative effects of radiation? } & Yes & 73 & 42.2 \\
\hline & No & 100 & 57.8 \\
\hline \multirow{5}{*}{$\begin{array}{l}\text { What are the protective method you use to protect yourself from the negative effects of } \\
\text { radiation? }\end{array}$} & Lead apron & 169 & 45.7 \\
\hline & Thyroid shield & 138 & 37.0 \\
\hline & Gonadal protector & 21 & 5.7 \\
\hline & Gloves & 32 & 8.6 \\
\hline & Goggles & 11 & 3.0 \\
\hline \multirow[t]{2}{*}{ Is there a radiation warning sign in the area you work? } & Yes & 115 & 66.5 \\
\hline & No & 58 & 33.5 \\
\hline
\end{tabular}


areas, $115(66.5 \%)$ participants stated that there were warning signs in areas where radiation is used. Among participants who confirmed the presence of warning signs in radiation areas, 42 (36.5\%) worked in state hospitals, while only 16 (13.9\%) worked in private hospitals.

\section{Discussion}

The discovery of X-rays and radium, their use in medical applications and the emergence of harmful radiation effects on hospital staff underscore a need for radiation protection awareness [9]. Although exposure to radiation in medical imaging devices is minimized by technology, they are not entirely negligible. Since radiation has stochastic dose-dependent and dose-independent cancercausing effects [10], and given the cumulative radiation doses healthcare workers (e.g. operating room staff) are exposed to over time, there is an increased risk of cancer and radiation-related illnesses among these groups [10]. It is therefore imperative that healthcare workers using radioactive technologies such as fluoroscopes comply with the principles of ALARA ("as low as reasonably achievable"[9]. Indeed, the most important form of protection from the health risks associated with radiation exposure is the use of appropriate radiation-specific PPE $[11,12]$.

Our study is the first to evaluate awareness among urology staff about the systemic effects of ionizing radiation in Turkey. We found that the responses regarding the negative effects of radiation on organ systems were not influenced by whether participants received training. This further illustrates that radiation education may need to be revised.

Many studies have shown that most urologists do not take proper protective measures during fluoroscopy procedures and neglect to use proper PPE [10, 13, 14]. As previously reported $[1,8]$, our findings showed that urologists and their assistants are exposed to higher single doses of radiation during a procedure, while other personnel are exposed to higher cumulative radiation doses over time. In a study by Söylemez et al., they showed that not all urology healthcare workers used a dosimeter nor did they don adequate PPE [4]. In another study, the same group also revealed that urologists do not regularly use gonadal protection [5].

In this study, we found that irrespective of their occupation, half of the participants wore lead aprons and almost a third used thyroid protectors. The proximity of personnel to the fluoroscope during procedures may explain this observation. Indeed, most faculty members and residents, but none of the nurse respondents, stated that they used gonadal protection. When we assessed adherence to the usage of safety glasses and gloves, faculty members and assistants weakly complied with the use of these types of PPE, while nurses and radiology technicians showed strong compliance. One possible explanation for this observation is that safety glasses might impair the physician's vision during the procedure, which could influence compliance with this type of PPE.

Similar to our study, others have shown that lead aprons and thyroid protectors are more commonly used than other types of PPE $[10,11]$. While we expected to see a relationship between education level and PPE compliance, the observed findings did not reveal such a correlation. Hence, we agree with the explanation put forth by Söylemez et al. that these types of PPE are nonergonomic and thus affected PPE compliance among the participants in our study [4]. Furthermore, many studies have shown that urology operating room staff receive insufficient training on the dangers of radiation [15-18]. With only $42.2 \%$ of respondents receiving radiation-specific safety training, our findings suggest that this has still not improved among personnel working in the urology field.

The individual permissible radiation dose is determined by law [19], and it has been advised that dosimetry is used in cases where threshold values are exceeded [1]. In our study, we found that $43.3 \%$ of the participants used dosimetry. While all radiology technicians stated that they used dosimetry, a similar level of compliance was not observed in the other groups. Interestingly, dosimeter usage was more commonly practised among participants in education, research and state hospitals, which may be related to more frequent fluoroscope usage in these centres.

Warning signs must be used in areas where there is a high risk of radiation exposure to increase patient and staff member safety. As such, radiation warning signs should be posted in areas where fluoroscopy is used. However, only $66.5 \%$ of the participants stated that there was such a warning sign in their working environment. This could be because the warning signs posted are not striking enough to capture the personnel's attention. Thirty-seven per cent of participants stated that they performed fluoroscopy at least 4 times in their daily practice. Of these respondents $12.1 \%$ were radiology technicians, $8.1 \%$ were auxiliary healthcare personnel, and $5.8 \%$ were assistants. Despite such regular fluoroscopy usage, there is gravely insufficient awareness about the dangers of radiation and the use of PPE.

The main limitation of this research is the small numbers of respondents that fully completed the survey. The small number may be related to the fact that internet usage is not a preferred tool. However, this questionnaire has further underscored the lack of radiation safety compliance in Turkey. Reaching the participants online was another limitation. However, our approach enabled 
anonymity and allowed participants adequate time to reflect on their answers, rather than providing an answer immediately.

Though similar to previously published studies, our study is significant because it highlights the current state of radiation awareness among urology operating room staff at all levels in Anatolia, Turkey.

\section{Conclusion}

Full awareness of radiation protection is still not observed today. Compliance with ALARA principles is important in all areas of radiation exposure-both for the general and occupational health of fluoroscopy practitioners and also in terms of the additional burden imposed on the health economy. During their training, doctors and other healthcare practitioners using radiological instruments should be appropriately instructed on proper radiation protection. Improving the ergonomics of PPEs will help to ensure ease of use by the employee. Lastly, strict compliance with radiation safety measures and adherence to state-regulated ambient radiation levels should be monitored by the appropriate authorities.

\section{Abbreviations}

PPE: Personal protective equipment; ALARA: As low as reasonably achievable; mSv: Millisievert.

\section{Acknowledgements}

Not applicable.

\section{Author contributions}

All authors have read and approved the manuscript. RG performed planning and design, writing, data collection and analysis, and supervision.

\section{Funding}

The authors did not receive any funds for this study.

\section{Ethics approval and consent to participate}

All procedures performed in this study involving human participants were in accordance with the ethical standards of the institutional and/or national research committee and with the 1964 Helsinki declaration and its later amendments or comparable ethical standards. This study was approved by the ethics committee of Zonguldak Bulent Ecevit University Local Ethics Committee (Date of the meeting: 08.07.2020 Protocol number: 2020/14). Informed written consent was obtained before operation from all individual participants included in the study.

\section{Consent for publication}

Not applicable.

\section{Availability of data and material}

Available.

\section{Competing interests}

The authors declare that they have no conflict of interest.

Received: 14 October 2020 Accepted: 28 December 2020

Published online: 22 January 2021

\section{References}

1. Tok A, Akbas A, Aytan N et al (2015) Are the urology operating room personnel aware about the ionizing radiation? Int Braz J Urol 41(5):982-989

2. Rassweiler JJ, Serdar GA, Klein J et al (2019) 50 Jahre Minimal-invasive Chirurgie in der Urologie [50 years of minimally invasive surgery in Urology]. Aktuelle Urol. 50(6):593-605

3. The 2007 Recommendations of the International Commission on Radiological Protection. ICRP publication 103. Ann ICRP. 2007;37:1-332.

4. Soylemez H, Altunoluk B, Bozkurt Y et al (2012) Radiation exposure-do urologists take it seriously in Turkey? J Urol 187:1301-1306

5. Sancaktutar AA, Atar M, Soylemez H et al (2011) Habits and awareness of Turkish urologists about using gonad protective. Eur Urol Suppl 10:578

6. Bush WH, Jones D, Brannen GE (1985) Radiation dose to personnel during percutaneous renal calculus removal. AJR Am J Roentgenol 145:1261-1264

7. Hellawell GO, Mutch SJ, Thevendran G et al (2005) Radiation exposure and the urologist: What are the risks? J Urol 174:948-952

8. Kumari G, Kumar P, Wadhwa P et al (2006) Radiation exposure to the patient and operating room personnel during percutaneous nephrolithotomy. Int Urol Nephrol 38:207-210

9. King JN, Champlin AM, Kelsey CA et al (2002) Using a sterile disposable protective surgical drape for reduction of radiation exposure to interventionalists. AJR 178:153-157

10. Söylemez H, Sancaktutar AA, Silay MS et al (2013) Knowledge and attitude of European urology residents about ionizing radiation. Urology 81(1):30-35

11. Friedman AA, Ghani KR, Peabody JO et al (2013) Radiation safety knowledge and practices among urology residents and fellows: results of a nationwide survey. J Surg Educ 70:224-231

12. Shortt CP, Malone L, Thornton J et al (2008) Radiation protection to the eye and thyroid during diagnostic cerebral angiography: a phantom study. J Med Imaging Radiat Oncol 52:365-369

13. Giblin JG, Rubenstein J, Taylor A et al (1996) Radiation risk to the urologista during endourologic procedures, and a new shield that reduces exposure. Urology 48:624-627

14. Shiralkar S, Rennie A, Snow M et al (2003) Doctors' knowledge of radiation exposure: questionnaire study. BMJ 327:371-372

15. Arslanoğlu A, Bilgin S, Kubal Z, et al. Doctors' and intern doctors' knowledge about patients' ionizing radiation exposure doses during common radiological examinations. Diagn Interv Radiol. 2007;13:53-55.

16. McCusker MW, de Blacam C, Keogan M et al (2009) Survey of medical students and junior house doctors on the effects of medical radiation: is medical education deficient? Ir J Med Sci 178:479-483

17. Zhou GZ, Wong DD, Nguyen LK et al (2010) Student and intern awareness of ionising radiation exposure from common diagnostic imaging procedures. J Med Imaging Radiat Oncol 54:17-23

18. Soye JA, Paterson A (2008) A survey of awareness of radiation dose among health professionals in Northern Ireland. Br J Radiol 81:725-729

19. Turkish Atomic Energy Authority. Radiation Safety Regulation Issue Date of Official 